\title{
Endoscopic Submucosal Dissection of an Inverted Pyloric Gland Adenoma Using Dental Floss and Clip Traction
}

\author{
Gwang Ha Kim', Moon Won Lee', Bong Eun Lee ${ }^{1}$ and Do Youn Park ${ }^{2}$ \\ ${ }^{1}$ Department of Internal Medicine, Pusan National University College of Medicine and Biomedical Research Institute, Pusan National \\ University Hospital, Busan, ${ }^{2}$ St. Mary Pathology Laboratory, Busan, Korea
}

A gastric adenoma with low-grade dysplasia was incidentally detected during screening endoscopy in a 52-year-old woman. The endoscopy revealed a reddish elevated lesion with a diameter of $1.5 \mathrm{~cm}$ and an opening on the greater curvature of the upper body (Fig. 1A). Endoscopic ultrasonography of the lesion revealed a downward papillary growth into an anechoic cystic space of approximately $2 \mathrm{~cm}$ in size in the deep mucosal and submucosal layers (Fig. 1B). Endoscopic submucosal dissection (ESD) was performed for complete removal of the adenoma and accompanying cystic lesion (Supplementary
Video 1).

After the borders of the tumor were marked, a $0.9 \%$ saline solution with indigo carmine and epinephrine was injected in the submucosal layer. Circumferential mucosal incision and submucosal dissection were then performed using a dual knife and an insulated-tipped knife. During dissection, a clip attached with dental floss was used to secure the dissection plane between the tumor and the proper muscle layer (Fig. 1C). The tumor was then completely resected (Fig. 1D).

Histopathological examination revealed that the cystic in-
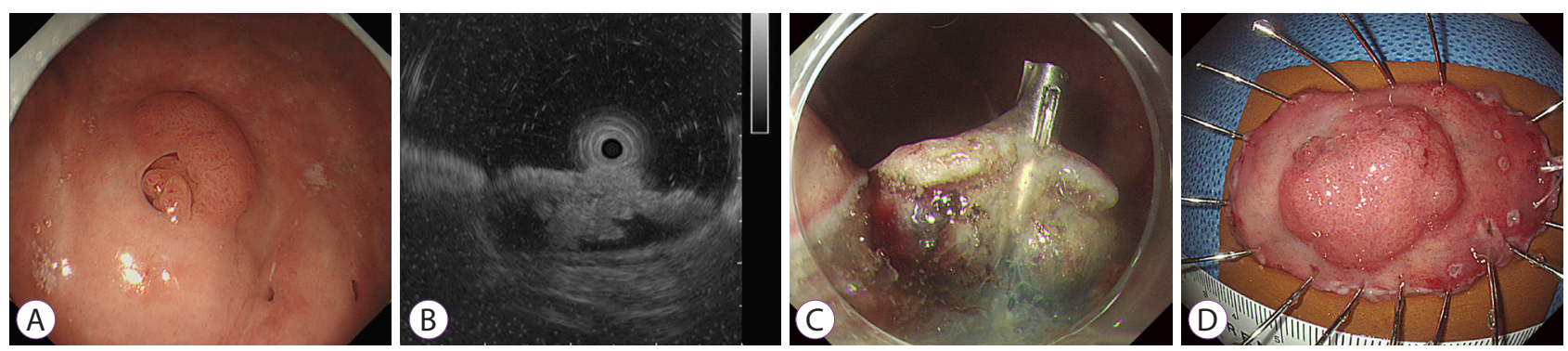

Fig. 1. (A) A reddish elevated lesion with a diameter of $1.5 \mathrm{~cm}$ and an opening on the greater curvature of the gastric upper body. (B) Endoscopic ultrasonography of the lesion showing a downward papillary growth into an anechoic cystic space of approximately $2 \mathrm{~cm}$ in size in the deep mucosal and submucosal layers. (C) During endoscopic submucosal dissection, the dissection plane is secured between the tumor and the proper muscle layer using a clip attached with dental floss. (D) The resected specimen.

Received: June 15, 2020 Revised: June 29, 2020

Accepted: July 12, 2020

Correspondence: Gwang Ha Kim

Department of Internal Medicine, Pusan National University College of Medicine and Biomedical Research Institute, Pusan National University Hospital, 179 Gudeok-ro, Seo-gu, Busan 49241, Korea

Tel: +82-51-240-7869, Fax: +82-51-244-8180, E-mail: doc0224@pusan.ac.kr

ORCID: https://orcid.org/0000-0001-9721-5734

(c) This is an Open Access article distributed under the terms of the Creative Commons Attribution Non-Commercial License (http://creativecommons.org/licenses/by$\mathrm{nc} / 3.0$ ) which permits unrestricted non-commercial use, distribution, and reproduction in any medium, provided the original work is properly cited. 

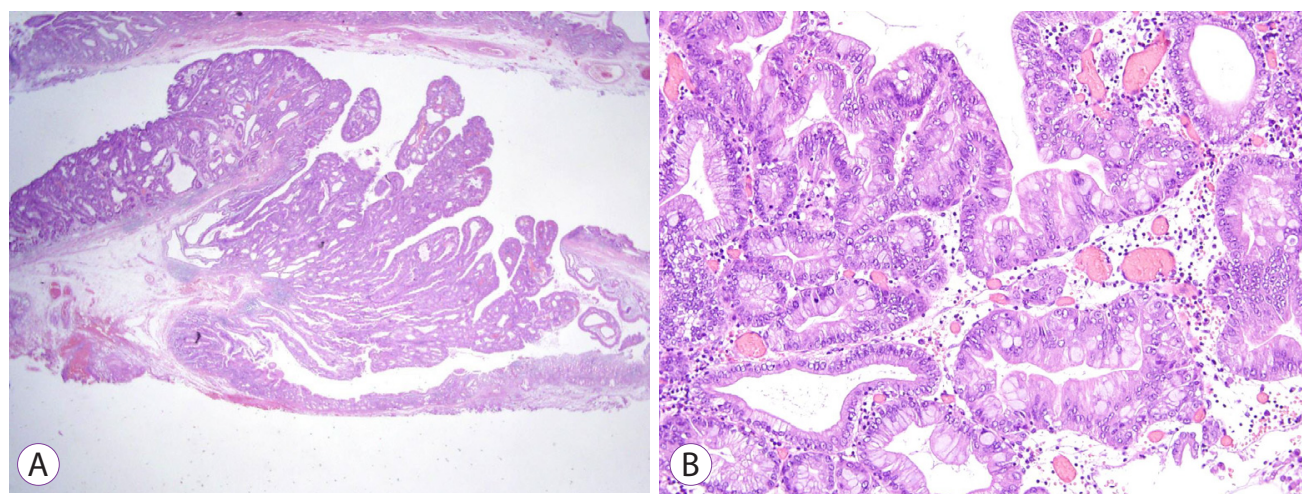

Fig. 2. (A) Histopathological examination showing that the cystic invagination of the mucosal lesion is composed of neoplastic glands with high-grade dysplasia (hematoxylin and eosin stain $\times 12.5$ ). (B) Most of the glandular cells have round nuclei with prominent nucleoli and mucinous columnar cytoplasm that resemble the pyloric glandular epithelium (hematoxylin and eosin stain $\times 200$ ).

vagination of the mucosal lesion was composed of neoplastic glands with high-grade dysplasia. Most of the glandular cells had round nuclei with prominent nucleoli and mucinous columnar cytoplasm that resemble the pyloric glandular epithelium (Fig. 2). Therefore, the lesion was diagnosed as an inverted pyloric gland adenoma with high-grade dysplasia.

Pyloric gland adenoma is a rare neoplasm, and the histological resemblance of the tumor to the deep glands of the gastric mucosa near the pylorus is reflected in its name. ${ }^{1}$ It occurs more frequently in women and in the elderly. As adenocarcinoma is detected in approximately $30 \%$ of pyloric gland adenomas, ${ }^{2}$ they are considered precancerous lesions, and endoscopic removal is indicated. ${ }^{3}$ As described in our report, ESD using dental floss and clip traction seems to be an efficient and safe technique for inverted pyloric gland adenomas, especially when the tumor is located in the greater curvature of the upper or middle stomach. ${ }^{4}$

Conflicts of Interest

The authors have no potential conflicts of interest.

Funding

None.

ORCID

Gwang Ha Kim:

Moon Won Lee:

Bong Eun Lee:

Do Youn Park: https://orcid.org/0000-0001-9721-5734 https://orcid.org/0000-0002-8411-6398 https://orcid.org/0000-0003-2734-2134 https://orcid.org/0000-0001-7641-1509

Supplementary Material

Video 1. Endoscopic submucosal dissection of an inverted pyloric gland adenoma (https://doi.org/10.5946/ce.2020.164.v001).

\section{REFERENCES}

1. Golger D, Probst A, Wagner T, Messmann H. Pyloric-gland adenoma of the stomach: case report of a rare tumor successfully treated with endoscopic submucosal dissection. Endoscopy 2008;40(Suppl 2):E110-E111.

2. Oberhuber G, Stolte M. Gastric polyps: an update of their pathology and biological significance. Virchows Arch 2000;437:581-590.

3. Yamamoto M, Nishida T, Nakamatsu D, Adachi S, Inada M. Endoscopic findings of inverted pyloric gland adenoma resected by endoscopic submucosal dissection. J Gastrointestin Liver Dis 2018;27:361.

4. Yoshida M, Takizawa K, Suzuki S, et al. Conventional versus traction-assisted endoscopic submucosal dissection for gastric neoplasms: a multicenter, randomized controlled trial (with video). Gastrointest Endosc 2018;87:1231-1240. 